\title{
Menuju Sekolah Siaga Bencana di SD Muhammadiyah Klaten Utara
}

\author{
Nursetiawan', Rama Okta Wiyagi ${ }^{1}$ \\ 1) Program Studi teknik Sipil, Fakultass teknik, Universitas Muhammadiyah Yogyakarta, Jl. Brawijaya, Geblagan, Tamantirto, Kec. Kasihan, \\ Yogyakarta, Daerah Istimewa Yogyakarta 55183 \\ Email: nursetiawan@umy.ac.id \\ DOI: $10.18196 / p p m .36 .327$
}

\begin{abstract}
Abstrak
Muhammadiyah memiliki amal usaha termasuk bidang pendidikan mulai dari tingkat Pendidikan Dini sampai dengan Pendidikan Tinggi dengan jumlah mencapai ribuan yang tersebar di seluruh wilayah Indonesia. Membangun kesadaran akan kesiapsiagaan bencana oleh seluruh komponen masyarakat, termasuk oleh sekolah-sekolah sangat diperlukan mengingat kondisi Indonesia yang secara geografis terletak di wilayah dengan tingkat kerawanan terhadap bencana cukup tinggi. Kaitannya dengan upaya penanggulangan bencana di Indonesia, sekolah-sekolah Muhammadiyah sebagai bagian ruang publik harus memiliki peran nyata dalam membangun ketahanan masyarakat melalui program sekolah siaga bencana. Kegiatan Pengabdian Kepada Masyakat UMY berupa program kesiapsiagaan bencana telah dilakukan di SD Muhammadiyah Klaten Utara berkerja sama dengan BPBD Kabupaten Klaten. Walaupun ditengah situasi pandemi covid-19, kegiatan dilakukan dengan melihatkan pihak guru-guru sekolah sekaligus juga dengan pemasangan alat pendeteksi getaran gempa sebagai bagian early warning system dan juga sebagai media pihak sekolah untuk melakukan simulasi terhadap para siswa.
\end{abstract}

Kata Kunci: sekolah siaga bencana , mitigasi bencana, simulasi kebencanaan, alarm getar

\section{Pendahuluan}

Indonesia merupakan salah satu negara yang mempunyai tingkat kerawanan bencana alam cukup tinggi. Berdasarkan data World risk report 2018, Indonesia menduduki urutan ke36 dari 172 negara paling rawan bencana alam di dunia (Hadi et al, 2019). Berdasarkan fakta ilmiah inilah, Indonesia perlu benar-benar mempersiapkan diri dalam menghadapi bencana alam. Masyarakat perlu memiliki kesadaran tinggi terkait mitigasi bencana demi menekan risiko kebencanaan termasuk jumlah korban jiwa. Sebagai contoh, tercatat ratusan ribu korban jiwa berjatuhan pasca bencana alam seperti gempa bumi yang pernah terjadi di Indonesia. Tingginya angka korban jiwa dan kerugian harta benda menjadi indikasi rendahnya kesiapsiagaan stakeholder (multipihak) dalam menghadapi bencana alam.

Faktor yang berpengaruh dalam kesiapsiagaan bencana antara lain faktor pengetahuan terhadap kesiapsiagaan bencana, sikap dalam kesiapsiagaan bencana, kebijakan dan panduan, rencana untuk keadaan darurat bencana, sistem peringatan bencana, dan mobilisasi sumber daya (Husna 2011 dalam Hastuti et al, 2020). Pemberian pelatihan simulasi sangat penting untuk meningkatkan kesiapsiagaan masyarakat akan bahaya bencana, semakin baik dan semakin sering dilakukan pelatihan simulasi bencana, maka semakin siap dalam menghadapi bencana (Hastuti et al, 2020).

Salah satu bentuk sosialisasi budaya sadar bencana adalah melalui Sekolah Siaga Bencana. Siswa sekolah dirasa perlu mendapat pelajaran tentang kesiapsiagaan secara teratur dan menerus. Di sekolah, siswa-siswa menghabiskan lebih dari enam jam kesehariannya. Oleh karena itu, pendidikan kebencanaan untuk mitigasi kultural, terutama yang mengarah pada jenis bencana di daerah tersebut, dirasa paling penting untuk dilakukan. Hal ini termasuk di Sekolah Dasar Muhammadiyah Klaten Utara dengan jumlah siswa yang cukup besar, perlu mulai menerapkan kesiapsiagaan menghadapi bencana dengan melakukan sosialiasi dan simulasi secara rutin kepada seluruh siswa dan juga tenaga pendidik yang ada di sekolah.

SD Muhammadiyah Klaten Utara merupakan sekolah dasar yang didirikan oleh yayasan 
Muhammadiyah pada Tahun 2012 di Kelurahan Bareng Lor, Kecamatan Klaten Utara, Kabupaten Klaten, Provinsi Jawa Tengah. Adapun permasalahan yang dimiliki terkait kesiapan menjadi Sekolah Siaga Bencana antarai lain sekolah belum melakukan kajian risiko bencana di sekolah; belum memahami kesiapsiagaan dalam menghadapi bencana, dan rencana aksi penanggulangan bencana jika terjadi saat siswa berada di sekolah. Oleh karena itu tujuan kegiatan pengabdian masyarakat ini adalah untuk memberikan pendampingan dan pelatihan serta pengadaan alat-alat agar siap menuju sekolah siaga bencana. Siswa sekolah dirasa perlu mendapat pelajaran dan pelatihan tentang kesiapsiagaan secara teratur dan menerus. Di sekolah, anak-anak menghabiskan lebih dari enam jam kesehariannya. Oleh karena itu, pendidikan kebencanaan untuk mitigasi kultural, terutama yang mengarah pada jenis bencana di daerah tersebut, dirasa sangat penting untuk dilakukan.

\section{Metode Pelaksanaan}

Untuk menyelesaikan permasalahan yang dihadapi mitra terhadap kesiapsiagaaan bencana, maka akan dilakukan sosialisai pengurangan risiko bencana serta simulasi ketika menghadapi bencana. Secara khusus, pengurangan risiko bencana (PRB) dilaksanakan sebagai tanggapan terhadap (1) frekuensi kejadian bencana dan tingkat kerusakan maupun korban jiwa semakin meningkat di Indonesia, (2) belum banyak institusi yang mengerjakan pendidikan kebencanaan sebagai fokus kegiatan, (3) respon positif masyarakat terhadap kegiatan penelitian dan pengabdian masyarakat bidang kebencanaan, dan (4) pendidikan pengurangan resiko (mitigasi) bencana menjadi agenda yang mendesak untuk dilakukan baik lokal, regional, dan nasional.

Adapun metode pelaksanaan kegiatan yang dilakukan meliputi:

a) Analisis situasi awal dan koordinasi dengan pihak sekolah

Tahap persiapan berupa pengumpulan data-data mengenai MBS SD Muhammadiyah Klaten Utara, penentuan jadwal dan lokasi kegiatan.

b) Pendalaman karakteristik lokasi dan pembuatan peta situasi Sekolah

c) Pemilihan titik kumpul, rute dan pemasangan jalur evakuasi untuk memberikan penanda rute dan titik kumpul yang tepat untuk menyelamatkan diri saat terjadi bencana

d) Pemasangaan Alat Deteksi Getaran (Gempa Bumi)

Pemasangan alat deteksi getaran gempa bumi dimaksudkan untuk memberikan peringatan dini kepada seluruh warga sekolah agar siap dan waspada serta dapat melakukan tindakan dini untuk menyelamatkan diri sebelum bencana terjadi.

e) Sosialisasi Kesiapsiagaan dan Simulasi Bencana

Memberikan pemahaman kepada siswa dan guru tentang arti bencana, macam bencana, pengurangan resiko bencana, kerentanan bencana dan penjelasan secara umum tentang Sekolah Muhammadiyah Tangguh Bencana. Sedangkan kegiatan simulasi dimaksudkan untuk memberikan pemahaman kepada siswa dan guru tentang hal-hal yang perlu dilakukan sebelum, saat, dan setelah terjadi bencana secara umum, dan bencana gempa bumi secara khusus.

f) Evaluasi pelaksanaan program

\section{Hasil dan Pembahasan}

Dalam tahap awal kegiatan, telah dilakukan pemetaan situasi sekolah untuk memudahkan penentuan alternatif jalur evakuasi yang paling memadai dan selanjutya dimbarkan dalam bentuk peta denah. Prasarana SD Muhammadiyah Klaten Utara adalah berupa ruangan dengan jumlah 15 yang terdiri ruang kelas, perpustakaan dan laboratorium komputer. 
Dari denah ruangan ruangan-ruangan tersebut selanjutnya ditentukan jalur evakuasi dengan papan petunjuk, pilihan titik kumpul (assembly point), lokasi pemasangan alat deteksi getaran. Denah situasi lingkungan SD Muhammadiyah Klaten Utara seperti disajikan pada Gambar 1. Kondisi sekolah dengan presfektif tampak gedung sekolah dari semua arah digambarkan dalam bentuk 3D dengan menggunakan aplikasi skecth-up. Gambar 3D ini telah diserahkan kepada pihak sekolah untuk dapat dijadikan gambar acuan dalam rangka pengembangan sekolah ke depan dan juga dalam kaiatnnya dengan kegiatan terkait kebencanaan. Gambar presfektif 3D sekolah disajikan pada Gambar-2.

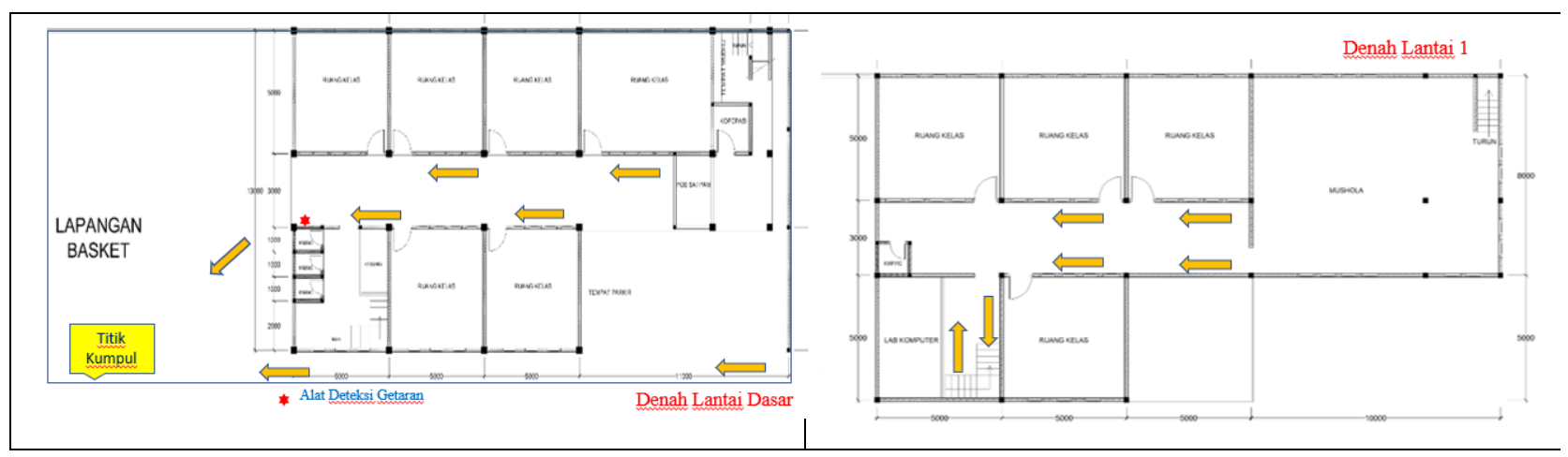

Gambar 1. Denah ruangan sekolah dan rute jalur evakuasi
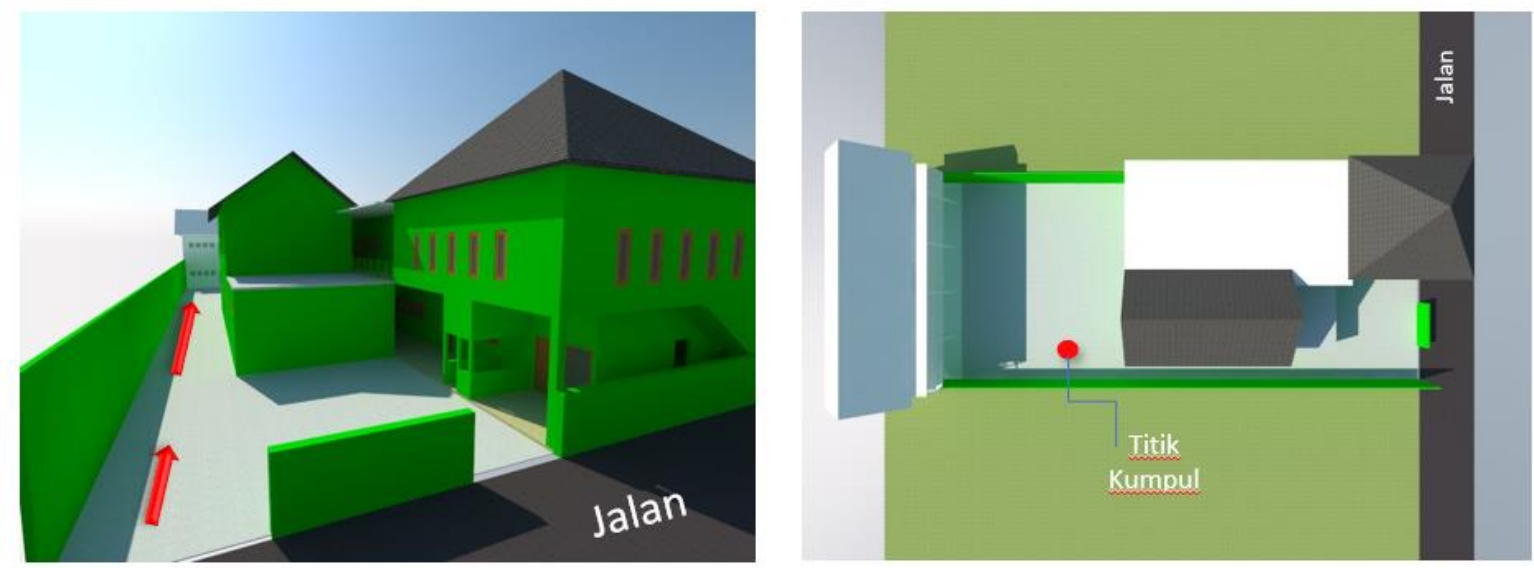

Gambar 2. Prespektif 3D bangunan dan lingkungan sekolah

Iptek yang diaplikasi pada kegiatan pengabdian kepada masyarakat ini adalah sebuat alat yang disebut Alarm Getar (Vibration Alarm), yaitu suatu alat elektronik yang mampu mendeteksi adanya getaran dan mampu membangkitkan suara peringatan ketika terjadi getaran. Pendeteksian getaran menggunakan sensor getar berbasis transducer piezoelectric element. Getaran yang diterima sensor kemudian diubah menjadi besaran listrik untuk diumpankan pada kontroler. Kontroler akan mengolah data dari sensor dengan memberikan nilai threshold tertentu terhadap sinyal getaran yang diterima. Jika dipastikan sinyal masukan dari sensor adalah getaran dengan intensitas tertentu maka kontroler akan mengaktifkan alarm. Gambar 3 menyajikan prinsip kerja serta foto dari alarm getar untuk pendeteksi getaran yang diserahkan kepapada pihak sekolah. Alat ini juga dapat digunakan oleh pihak sekolah untuk melakukan simulasi rutin agar seluruh siswa dapat berlatih secara terus menerus bagaimana cara menghadapi bahaya jika terjadi bencana.

Selanjutnya sebagai agenda utama dari pelaksanaan kegiatan, telah dilakukan sosialisasi tentang kebencanaan kepada pihak sekolah. Di awal kegiatan, telah ditetapkan bahwa kegiatan 
sosialisasi dan simulasi bencana akan diberikan kepada para siswa dan juga para guru di lingkungan sekolah. Sehubungan dengan adanya pandemi covid-19, di mana seluruh aktivitas belajar mengajar dilakukan secara online dari rumah sehingga tidak memungkinkan untuk melaksanakan kegiatan seperti rencana awal tersebut. Sebagai pengganti, maka kegiatan sosialisasi dan simulasi bencana diberikan kepada para guru dan karyawan, dengan harapan guru-guru sekolah secara berkelanjutan akan dapat memnberikan secara para siswa sebagai bagian dari aktivitas dan kurikulum sekolah. Kegiatan sosialiasi dan simulasi diselenggaran atas kerjasama dengan pihak BPBD Kabupaten Klaten yang telah memlilih perangkat dan personel untuk memberikan materi kepada mitra. Adapun dokumentasi kegiatan sosialisasi dan simulasi berserta pemasangan petunjuk jalur evakuasi dan titik kumpul disajikan pada Gambar-4 dan Gambar-5.

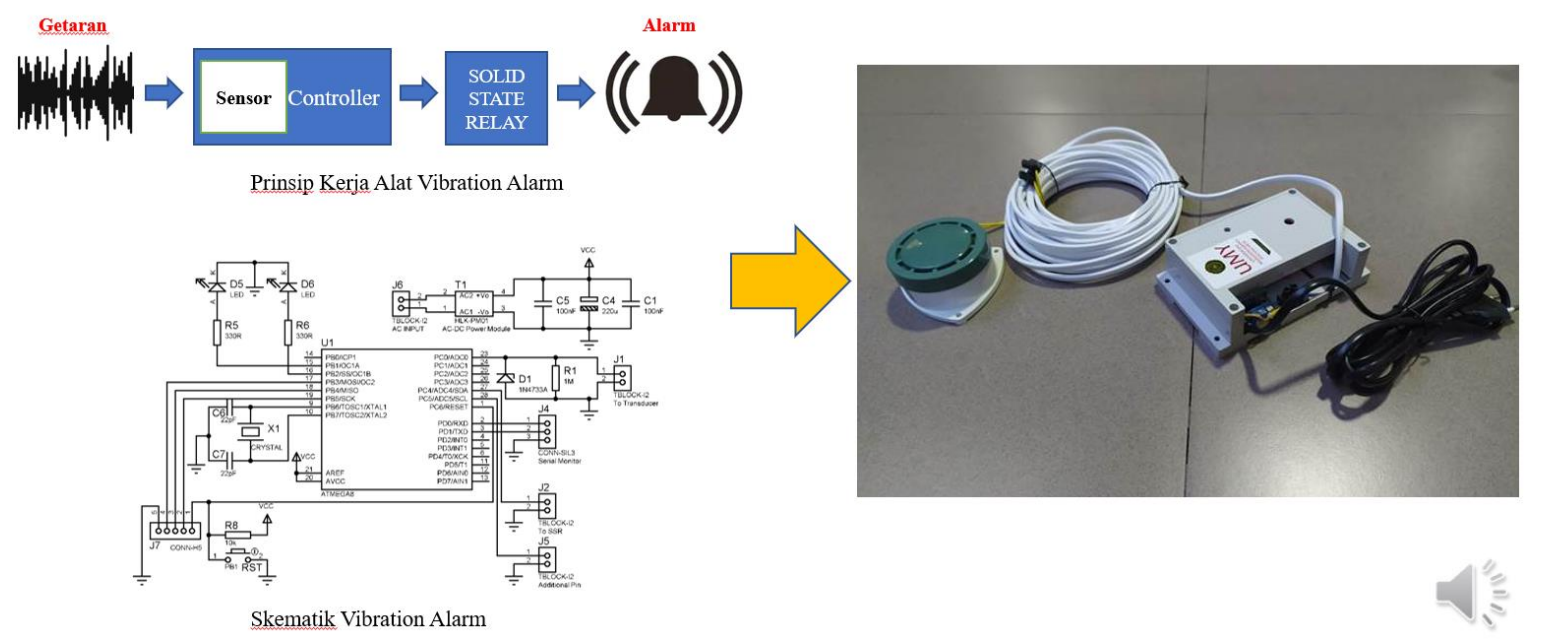

Gambar 3. Alat deteksi getaran dengan luaran bunyi alarm (alarm getar)
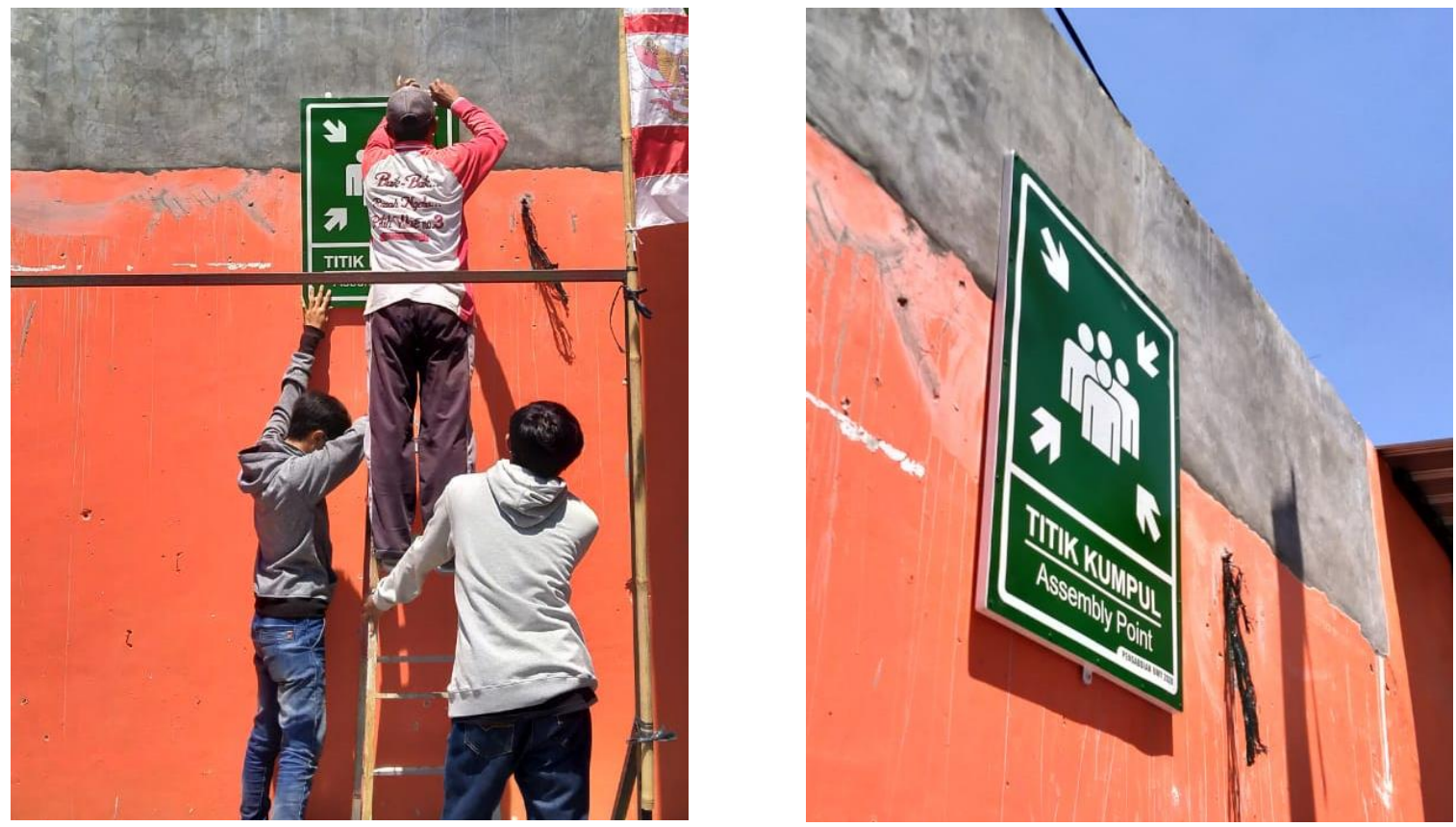

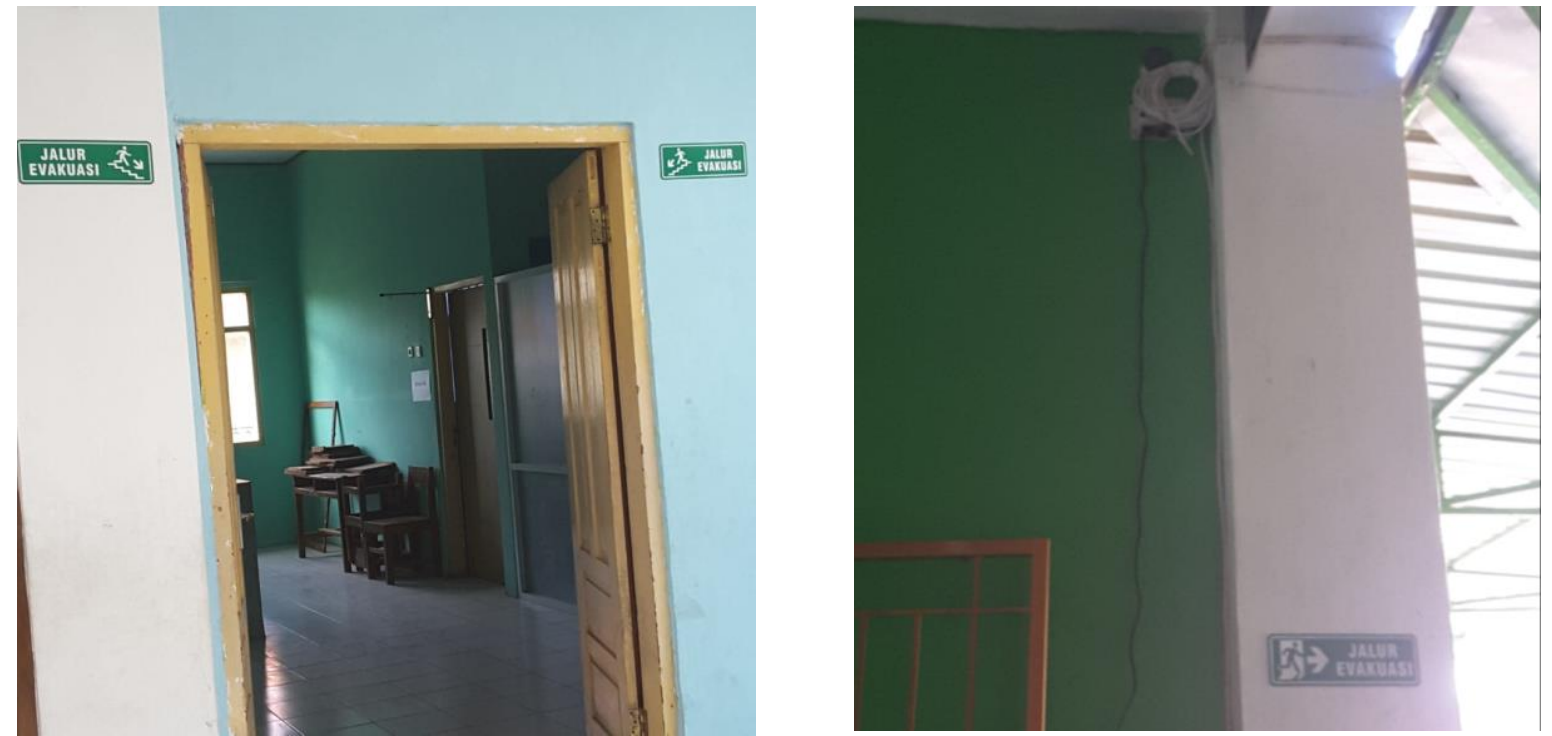

Gambar 4. Pemasangan papan petunjuk titik kumpul dan jalur evakuasi
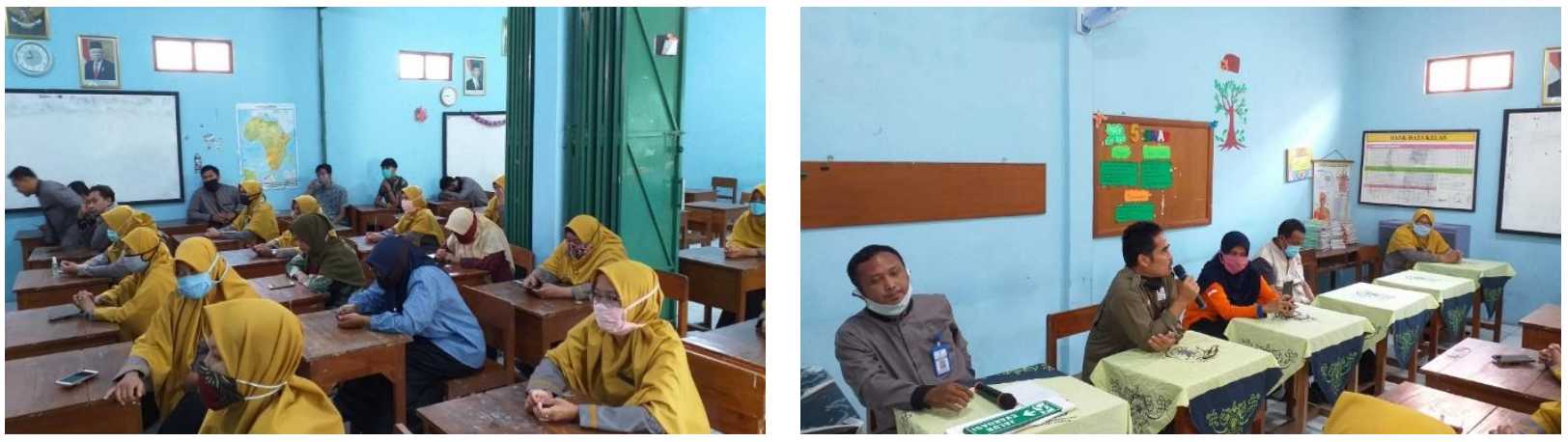

Gambar 5. Kegiatan sosialisasi dan simulasi dalam kesiapsiagaan menghadapi bencana

Sebagai evaluasi tindak lanjut kegiatan dan juga sebagai bagian dari tahapan menuju sekolah siaga bencana, pihak SD Muhammadiyah Klaten Utara selanjutnya telah membentuk kepanitian kebencanaan sekolah yang sekaligus digabungkan dengan kepanitian menghadapi pandemi covid-19 tingkat sekolah. Selain itu juga pihak sekolah telah menyusun pengadaaan kelengkapan-kelengkapan sekolah dalam menghadapi bencana seperti alat kebakaran, alat-alat P3K, tandu dan lain sebagainya. Pihak sekolah juga telah menyiapkan SOP-SOP mitigasi bencana sebagai panduan seluruh civitas akademik sekolah dalam menghadapi bencana dalam rangka menuju Sekolah Siaga Bencana.

\section{Simpulan}

Berdasarkan seluruh rangkaian kegiatan pengabdian kepada masyarakat ini, dapat diambil simpulan sebagai berikut:

- Sekolah menyambut sangat baik kegiatan sosialisasi dan simulasi menuju sekolah siaga bencana.

- Adanya pandemi covid-19, target simulasi kepada para siswa tidak dapat dilaksanakan. Sebagai penggantinya, sosialisasi dan simulasi diberikan kepada guru dan karyawan agar menjadi kegiatan yang berkelanjutan dan dapat diteruskan kepada para siswa.

- Tindak lanjut yang dilaksanakan pihak sekolah adalah berupa pembentukan kepanitiaan penganggulan bencana di tingkat sekolah dan penyusunan SOP sebagai panduan dalam langkah-langkah menghadapi bencana. 


\section{Ucapan Terima Kasih}

Ucapan terima kasih disampaikan kepada Universitas Muhammadiyah Yogyakarta atas hibah pengabdian kepada Masyarakat Tahun 2019/2020 dengan nomer kontrak: 031/PENLP3M/I/2020; Pihak Sekolah SD Muhammadiyah Klaten Utara; BPBD Kabupaten Klaten; Mahasiswa yang terlibat: Wahyu Eka Pratama (20170110007) dan Kresna Hendrayana (20180110107)

\section{Daftar Pustaka}

BNPB, 2016, RBI (Risiko Bencana Indonesia), Jakarta.

Kemendikbud, 2015, Modul Sekolah Aman, Jakarta.

Hasrul Hadi et al, 2019 , KESIAPSIAGAAN STAKEHOLDER DALAM PENGURANGAN RISIKO BENCANA GEMPABUMI. Jurnal Geodika Vol. 3, No. 1, Juni 2019, Hal. 30 - 40. e-ISSN 2549-1830.

Retno Yuli Hastuti et.al., 2020, ANALISIS FAKTOR-FAKTOR KESIAPSIAGAAN MASYARAKAT RAWAN BENCANA. Jurnal Ilmu Keperawatan Jiwa Volume 3 No 2, Hal 131 - 142, Mei 2020. e-ISSN 2621-2978, p-ISSN 2685-9394. 